\title{
Adopting New IT by Learning in Groups: Results of Discourse Analysis
}

\author{
Tanya V. Bondarouk \\ University of Twente \\ School of Business, Public \\ Administration and Technology \\ P.O. Box 2177500, AE \\ Enschede \\ The Netherlands \\ t.bondarouk@sms.utwente.nl
}

\author{
Huub J.M. Ruël \\ University of Utrecht \\ Utrecht School of Governance \\ Bijlhouwerstraat 6 \\ 3511 ZC Utrecht \\ The Netherlands \\ h.ruel@usg.uu.nl
}

\begin{abstract}
A new HR system was introduced into a Dutch hospital. The system implied collaborative work among its users. The project planning seemed to be reasonably straightforward: the system's introduction was intended to take place evolutionarily, including pilots in different departments and appropriate feedback. After some time, the system was successfully adopted by one group of users, but failed with another. We conceptualize the implementation process of groupware as a group learning to frame the adoption of the system, and analyze the qualitative data collected by means of discourse analyses carried out during the case study. We found that in the user-group with strong group learning, adoption of the system occurred effectively and on time. In another user-group with rather weak group learning, the use of the system was blocked after a short time. The results confirmed our assumption about the importance of group learning processes in the implementation of groupware.
\end{abstract}

\section{Introduction}

Decades of research and practical experience with the introduction of IT in organizations has made it clear that IT implementation tends to be an evolutionary process. Usually, a new system is introduced, the organization gathers experience, and then the system is fine-tuned according to the needs arising, in one or more cycles [1, $25,28,36]$. In this paper, we propose examining groupware implementation in a Dutch hospital.
Groupware technologies are known as a type of IT that helps groups work better through digital media $[1,18]$. Nowadays, more and more IT features collaborative technologies as the employees have to communicate with each other using it. Internet and mobile technologies, intranet services, networks within companies - they all have certain collaborative or groupware aspects. In our view, any kind of IT is interesting from a collaborative perspective if there is an interaction among its users.

We define groupware as any software program that facilitates and/or induces collaboration between endusers. These can be either dedicated programs (usual "groupware") or embedded fragments that are part of more general applications.

The question therefore arises as to how group interactional processes are related to the implementation of groupware. Some researchers have begun to acknowledge that the group processes do support implementation of groupware. Particular interactional processes that influence IT adoption are emphasized in the literature [2]: reflective group processes [15, 33]; sharing understanding [23]; collaborative knowledge building [32].

We introduce a novel perspective, regarding an implementation process as group experiential learning [2, 19]. This allows us to broaden our understanding of the behavioral mechanism of groupware implementation by a group of users.

We view implementation as the adoption of the system during the transition period from the moment when a new system is technically installed to the 'moment' when the groups use this system successfully. 
Success of implementation is understood as stable use of the system by the targetted employees [3].

In this paper, we aim to explore differences in the adoption of a human management system between two groups of users that occurred in a hospital environment in the Netherlands. We start from the assumption that strong group learning supports groupware implementation, while weak group learning complicates implementation.

To investigate the relevance of our assumption, we carried out a longitudinal case study in a hospital where a human resource information system had been newly introduced to the users. We analysed the group learning and success of implementation through discourse analysis.

The structure of this paper is as follows: first, we present our theoretical framework, then we introduce the discourse analysis. After that, we discuss a case study using our theoretical framework and point out the weaknesses and the strengths of the implementation process. What could have been improved is summarized in a final concluding section.

\section{Group learning as a theoretical framework}

In a broad sense, learning is defined as changing behavior and knowledge [5, 6, 12, 16, 22, 24]. At the group level, learning - changing group behavior - occurs through actions carried out by the members of the group, by which they improve task performance [7, 30].

When a new technology is introduced to a group of users, learning develops through specific interactional processes among group members, through which they share knowledge, express their attitudes towards the system, exchange experience in working with the system, collectively plan further implementation, etc.

We define group learning as iterative changing of the group behavior that occurs through interactional processes in an evolutionary manner, balancing between exploration of new operations and exploitation of routine actions with the system. To provide insights into these processes, we build our understanding of group learning behaviors on the concept of experiential learning [19]. On the inter-personal level, its mechanism can be described as a cycle of five different learning activities: collective acting - collective reflecting - knowledge disseminating - sharing understanding - mutual adjustment (figure 1). These activities support obtaining new information on using the system, training skills, and exchanging experience among group members.
A learning cycle begins with the collective experiences and actions when employees are given a certain task to perform. Action refers to the goal-directed behaviors relevant to achieving the desired changes in objectives and strategies [30].

This stage turns to collective reflection - the extent to which members of the group reflect upon and

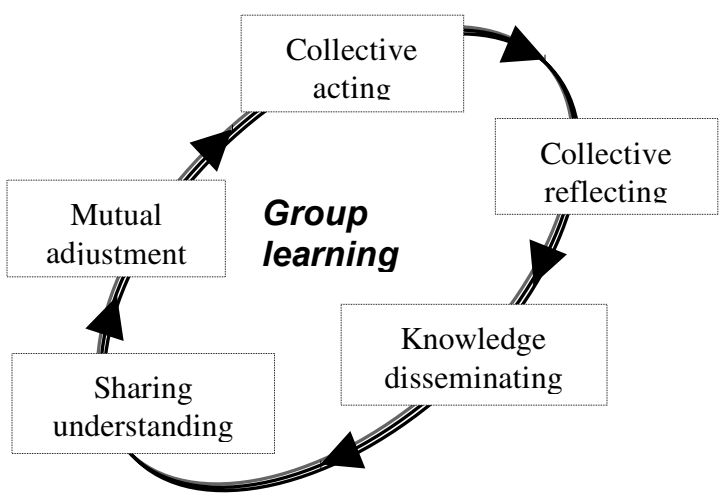

Figure 1: Group learning processes

communicate about the objectives and strategies (e.g. decision-making) and update them to the current circumstances. Reflection takes place through a variety of activities: discussions, collective debates, presentations that aim at knowledge externalization.

Knowledge dissemination implies mutual informal acceptance and respect for diverse ideas and suggestions. It can appear in many forms, including presentations, lectures, oral explanations of ideas, or "codifying it in any intelligent knowledge system" [14]. Subsequently, the cycle turns to sharing understanding. This involves using insights to help people see their own situation better [17]. Internalization also takes on a great variety of forms: learning by doing, reading books, etc. It is oriented to those people who look for acquisition of knowledge.

The last step in cooperative group learning is mutual adjustment. This supposes joint regulations, planning, arrangement, and decision-making. After planning is completed, its implemention starts, which provokes a new cycle beginning with collective action. A new learning cycle will be based on the previous group experience and knowledge. Planning can also take place during the action or while executing a task, when plans are developed and shaped by seeking feedback (group reflecting processes) that strengthens the importance of group reflexivity.

Taking into account an abstract level of the five steps, we emphasize that it is a theoretical construct that is 
helpful in our view to understand institutionalized use by groups of users [25].

\subsection{Group support factors}

It is wise to determine what types of groups we are looking for. Group type varies across several dimensions, including cross-functional versus single-function, shortterm project groups versus long-term, manager-led versus self-autonomous, etc. We assume that the group learning model can be applied across different types of groups, independent of their composition, functionality, level of autonomy, etc. because the social mechanism of collaborative learning concerns people taking action in the presence of others in a group.

For our research, what is important is not the system itself - whether it fits the well-accepted label of groupware or not - but the collaborative way people work with the system. Collaborative technologies require groups of employees (3 persons or more). We will label as a group any kind of collaborative unit which includes two or more employees engaged in a common task and performing that task through the system (or certain modules of the system).

Three factors, in our view, support collaboration within a group and are essential for the adoption of a new technological system: interpersonal understanding, task design and psychological safety.

Interpersonal understanding [6] means that colleagues working in the group understand each other's concerns, preferences, tendencies, and strengths. Similar variables can be found in the literature: personal relationships, awareness of team-mates' characteristics [5].

Task design characterizes the tasks that are performed by the group and to a certain extent supposed to be supported by the system. Task significance is the shared belief about the importance and significant consequences either for the company or for its customers [4, 12].

Psychological safety is understood as 'shared belief about the consequences of interpersonal risk-taking' [7]. This implies that the group will not embarrass, reject, or punish someone for speaking up. Research has shown that psychological safety was the most significant predictor of such activities as seeking feedback, experimenting, and discussing errors [7].

\section{Research site}

Our case study reports on the implementation of a personnel administration system - Beaufort - in one of the larger Dutch hospitals, called Medinet [29], which has 1070 beds and around 3700 employees. The project, involving acquisition of a new information system, development of the project plan, and realisation - started in June 1999 and was expected to be completed in December 2001.

The project had two planned phases: introduction of the system to the central personnel-and-salary (PSA) department, and introduction of the system across the entire Medinet. From our theoretical perspective, these became two distinguishable sub-cases. The PSA department implemented Beaufort effectively, efficiently, and in accordance with the initial plan (sub-case 1). The introduction of the same system to the personnel specialists in other departments failed, which led to the blocking of the whole project in October-November 2001 (sub-case 2).

\section{Technology introduced}

Introduction of Beaufort in Medinet aimed at:

- increasing the efficiency of personnel administration by restructuring of the personnel administration in the hospital from highly centralised to a decentralised manner;

- creating shared information files that could lead to using and exchanging personnel information among the managers;

- achieving consistency in the personnel data across all IT in Medinet.

Beaufort is a module-based personnel and salary administration system. There are seven strictly structured modules, within which you can perform document administration: salary administration, sick leave administration, personnel management, formation and organisation, time registration, Office Link, and report generator. In addition, the system contains technical possibilities for improvisation in generating, composing, structuring, and storing the data. The same document can be made through different operations, using different screens and tools.

\section{Research method}

In order to investigate the implementation process of Beaufort, we carried out the longitudinal case study in Medinet. It lasted for 10 months. Such a prolonged period [9] allowed us to process a large variety of research methods: interviews, document analysis, observations in the field, participating in team-building activities, etc. We were involved in a gradual process of implementing the system - discussing its issues with the 
steering group, and visiting and observing the targetted employees in their day-to-day work in a special medical environment.

A lot of information about the on-going development of the project was obtained in informal daily conversations with the project team members. They kept us up-to-date on different details of the Beaufort implementation. It helped us to develop a common language, to comprehend the professional lexicon used in Medinet, and to understand the culture of the company and sub-cultures of different departments. We appreciated the trust of the respondents that was built up during that period.

We studied documents such as the strategic plan, Beaufort project plan, the user manual, documents and protocols of the project steering group.

A detailed data collection was conducted through semi-structured interviews. We conducted 34 interviews lasting from 45 minutes to 2 hours each. Most of the interviews were one-on-one, but three group interviews were also done because of the office environment. Some of the interviews required two meetings, as there was a need for additional clarification and information.

\subsection{Discourse analysis: introduction of the method}

To analyse the gathered data, we used discourse analysis. Discourse refers to practices of talking and writing [35] which bring objects into being through the production, dissemination, and consumption of texts [13]. Discourse analysis, therefore, studies "all forms of spoken interaction, and written texts of all kinds" [27, p.7].

Discursive-based analysis is not new in the field of interpretive social studies [see 27, 31, 34]. However, until recently, much of this literature has tended to focus on the same institutional settings, discussing the basic theoretical antecedents, which are still acknowledged as somewhat less than clear [11]. Only during the last decade have management and organisational studies shown a keen interest in discourse, which has led to establishing a field of inquiry labelled "organisational discourse" [13, 26]. Discourse analysis is multidisciplinary in its origin - it is shaped by a variety of sociological, sociopsychological, anthropological, linguistic, philosophical, communications, and literaturebased approaches $[8,11,27,34,37]$. This multidisciplinary genesis provides different perspectives to what actually constitutes "discourse".
It starts from the fundamental assumptions that language is a medium oriented towards action and function, that people use language intentionally to construct accounts, or versions, of the social world [8]; and that one-to-one correspondence exists between a word (encoding of information) and its meaning (decoding of information) [37]. Therefore, the concept of variability is central to this approach because the words and their meaning will vary depending on their function.

The texts used for analysis can be formal written records, such as news reports, company statements and reports, academic papers; transcripts of social interactions such as conversations, focus group discussions, and individual interviews; or involve media such as TV programmes, advertisements, magazines, and novels. Sample size is not usually a main issue in discourse analysis as the interest is in the variety of ways the language is used [27]. Large variations in linguistic patterning can emerge from a small number of people. So a larger sample size may just make the analytic task unmanageable rather than adding to the analytic outcomes.

Four themes in discourse analysis can be distinguished as different research foci. First is the discourse itself, or texts in their own rights, without assumptions about something meant behind the text. Second is that language is used to construct the social world rather than being a transparent medium of it [27]. Third is the practical orientation of discourse - its occurrence in a particular interpretive context [10]. Fourth is the rhetoric used in the texts [27].

There are different analytical approaches applied to above-mentioned themes. As Gill [10] has noted, "it is much easier to explicate the central tenets of discourse analysis that it is to explain how actually to go about analyzing discourse" (p. 143). In approaching it, one walks through a 'recipe book' of prescribed phases or attempts to follow an unstructured, seemingly mysterious path. The design of the approach, in our view, is dependent on the researcher's world view and the special goals of the projects, which vary from a fine-grained study of linguistic features [34] to the dominant themes in the respondents' discourse. Either of these extremes demands that researchers make a shift from seeing discourse as reflecting social reality to the ways in which accounts are constructed and the functions they perform.

A widely acknowledged disadvantage of discourse analysis is its extreme labour intensity and time consumption. Transcription of audiotapes alone is already a challenging task. Reading, coding, and analysing the transcripts require painstaking efforts, too. 
In the next section, we describe the research approach conducted in our study, and the efforts put into it.

\subsection{Discourse analysis in this study}

The focus of our research was to obtain insights into the interpretive repertoires that employees of Medinet had regarding Beaufort adoption, as well as the extent to which these repertoires were used. By conducting interviews, we aimed both at encouraging the diversity of response and at obtaining consistency. We strove to stimulate variability by active intervention in the interview process and organising informal conversation exchange, by proposing confrontational statements [13], and by facilitating disagreements [8]. The emphasis during the interviews, therefore, was on the design of communication, where the interviewers were active participants rather than 'speaking questionnaires'.

The discourse analysis in this study is mainly based on the methodology proposed by Potter [27] and involves eight phases.

First: research questions. We determined the categories for coding based on our research interest, the literature search, and document analysis from Medinet. Then we operationalized the constructs of group learning and stable use (table 1).

\begin{tabular}{|c|c|}
\hline \multicolumn{2}{|c|}{$\begin{array}{c}\text { Adoption of the system - collaborative learning processes, } \\
\text { carried out by the group members, through which a group } \\
\text { improves use of the system. }\end{array}$} \\
\hline DIMENSIONS & COMPONENTS \\
\hline $\begin{array}{l}\text { 1. Collective acting - } \\
\text { task-related operations } \\
\text { with the system } \\
\text { undertaken by } \\
\text { members of a group. }\end{array}$ & $\begin{array}{l}\text { - operating with basic } \\
\text { modules in everyday } \\
\text { performance } \\
\text { - searching for } \\
\text { techniques in the system } \\
\end{array}$ \\
\hline $\begin{array}{l}\text { 2. Group reflecting - } \\
\text { communicating upon } \\
\text { extent to which the } \\
\text { system supports } \\
\text { performing tasks. }\end{array}$ & $\begin{array}{l}\text { discussing difficulties in } \\
\text { use of the system } \\
\text { comparing with another } \\
\text { software experience } \\
\text { - declaring individual } \\
\text { problems in use of the system }\end{array}$ \\
\hline $\begin{array}{l}3 . \text { Knowledge } \\
\text { disseminating } \\
\text { behaviors of the group } \\
\text { members that aim at } \\
\text { externalization of } \\
\text { ideas about the system } \\
\text { in order to improve its } \\
\text { usage. }\end{array}$ & $\begin{array}{l}\text { demonstration of operating } \\
\text { with technological options } \\
\text { - proposing new actions in } \\
\text { order to improve on-going use } \\
\text { - clarifying difficulties to } \\
\text { the team members }\end{array}$ \\
\hline
\end{tabular}

\begin{tabular}{|c|c|}
\hline $\begin{array}{l}4 . \text { Sharing } \\
\text { understanding - the } \\
\text { level of common } \\
\text { meaning of the system } \\
\text { regarding the role of } \\
\text { the system and its } \\
\text { functionality. }\end{array}$ & $\begin{array}{l}\text { - clearness about the purpose } \\
\text { of the system } \\
\text { users' needs in the system } \\
\text { - understanding of operating } \\
\text { with the modules in the system } \\
\text { attitudes towards } \\
\text { functionality of the system } \\
\text { - attitudes towards future } \\
\text { state of the system }\end{array}$ \\
\hline $\begin{array}{l}\text { 5. Mutual adjustment } \\
\text { - activities that aim at } \\
\text { collective agreements } \\
\text { on on-going use of the } \\
\text { system in the group. }\end{array}$ & $\begin{array}{l}\text { - arranging (further) learning } \\
\text { activities to improve use of the } \\
\text { system } \\
\text { - } \\
\text { - developing regulations } \\
\text { results }\end{array}$ \\
\hline \multicolumn{2}{|c|}{$\begin{array}{l}\text { Stable use of groupware - } \\
\text { task-consistent and skilful operation of the system. }\end{array}$} \\
\hline $\begin{array}{l}\text { 1. Ease-of-use }- \text { a } \\
\text { shared belief that use } \\
\text { of the system is } \\
\text { effortless for the } \\
\text { group. }\end{array}$ & $\begin{array}{ll}\text { - } & \text { speed of operating with } \\
\text { different modules } \\
\text { - } & \text { no difficulty in operating } \\
\text { - } & \text { friendliness of the interface }\end{array}$ \\
\hline $\begin{array}{l}\text { 2. Task-system fit }-\mathrm{a} \\
\text { shared belief that } \\
\text { using the system } \\
\text { assists executing the } \\
\text { group tasks (Lim and } \\
\text { Benbasat, 2000). }\end{array}$ & $\begin{array}{l}\text { - importance of the system } \\
\text { for the tasks } \\
\text { - availability of the data for } \\
\text { the members of the group } \\
\text { - match of the system with } \\
\text { the way of working in the group }\end{array}$ \\
\hline $\begin{array}{l}\text { 3. Efficacy beliefs - a } \\
\text { shared perception that } \\
\text { the group is capable of } \\
\text { improving on-going } \\
\text { use of the system } \\
\text { without external help. }\end{array}$ & $\begin{array}{l}\text { - group ability to perform } \\
\text { tasks using the system without great } \\
\text { efforts } \\
\text { - } \text { group ability to learn } \\
\text { (more) about the system without } \\
\text { external help }\end{array}$ \\
\hline
\end{tabular}

Table 1. Operationalisation of the constructs

Second: sample selection. The interviews were held with: the manager of the Concern Staff, the board member from the Department of Social Affairs, the manager of the PSA department, the project Beaufort manager, 3 members of the project Beaufort team, and Beaufort end-users (PSA department: 16 non-managerial employees, decentralised use: 4 HR local managers, 9 HR managerial employees, and 6 personnel secretaries).

Third: conducting interviews. We were actively involved in the conversation by asking provocative questions, confronting with opposite opinions, organising the dialogue. We interviewed 42 employees, which took us 48 hours.

Fourth: transcription. There is a certain variety in transcribing discourse from work attesting to the phonetic 
and intonational features. For our project, the lexicon used by employees was important - the texts and the contexts - in order to interpret the meaning of Beaufort adoption. The full transcription took 78 hours.

Fifth: member check. We discussed transcripts of all interviews with the respondents. It ensured correct and precise expressions for the textual analysis. In fact, this stage resembled a second round of interviews, which lasted from 15 minutes to 40 minutes each, in total 11 hours.

Sixth: coding. The two researchers who wrote this paper read all transcripts separately. They highlighted and selected all accounts that said something about the constructs and placed them into the framework. The result of this activity was two sets of expressions constructing the interpretive accounts of end-users per dimension.

Seventh: analysis. The researchers then gave labels to the expressions regarding group learning and stable use separately. They used the terms 'positive', 'negative', 'neutral', 'high', 'low', and 'moderate', but they also were open to new terms for labelling the expressions. This created the possibility of more refined labels. All expressions that could not be labelled with one of the terms mentioned were labelled as 'moderate'. Two examples:

\footnotetext{
"How intensively do I work with Beaufort? Would be wiser to ask if I have something without Beaufort..." (P12; ColAct-1.1-A)

"You can say whatever you want to the employees and promise them that Beaufort will improve their work. But first I want to get the answer to a simple question: who will be responsible for the mistakes made by local managers in Beaufort?..." (PSA-18, SharUnd-4.5-L)
}

Eighth: debriefing. Both researchers discussed and confronted each other with their preliminary results of analysis. It helped increase the sensitivity to the content of the accounts and the way the language was used by the interviewers. As an outcome of this stage, we agreed on our estimates of the interpretive repertoires of the employees regarding adoption of Beaufort.

\section{Findings}

We acknowledge but also accept that the way a text or a discourse is analysed and the findings are presented is very subjective and may not be the only valid interpretation. Our analysis may be only one of a number of possibilities.
Moreover, by focusing on one alternative, other explanations may even be missed or disregarded. Acknowledging that social scientific research is never value-free - whether advanced statistical procedures are applied or not - we believe that the data and findings are worth being taken into account because of several factors. First, our prolonged 10-month engagement in the research [Gardner]; second, labor intensity in interviewing, transcribing, and coding the accounts (more than 140 hours of work); third, feedback from all respondents on the transcripts (member check); fourth, peer debriefing - all contributed to the reliability of the study [20].

\subsection{Sub-case 1: Beaufort and PSA}

The main tasks of the PSA employees are to process the correct salary for the hospital staff and prepare salary documents on time. This involves more than 100 tasks that have to be performed in a cyclic way every month. The tasks were related to sick leave administration, registration of working hours and different types of contracts, pension management, supervision of financial projects, etc.

As a department, PSA members had a long experience of working together. Since 1999, they had been working as a team. All of them could execute all the tasks. However, usually they followed a scheduled plan where the tasks for a certain period were divided in such a way that everybody performed them in a cyclic manner. The level of individual responsibilities was very high: any mistakes could bring them into financial difficulty. They fed different salaryrelated data into the system (insurance, sick leave days, expenses declarations, vacation days, transport, etc.). Then during a certain week every month, they processed these data. The PSA employees benefited from the reliable and responsible work done by their colleagues.

The department consists of 18 employees: $70.6 \%$ female, $29.4 \%$ male; the average age is 33.4 years; the average period of employment in the department is 4.5 years; the education of $70 \%$ of the employees is at postsecondary school level.

Introduction of Beaufort aimed at supporting the main tasks of the PSA employees, and therefore the centrality of the system was high.

Introducing Beaufort did not demand changes in the content of job tasks. Due to the technical advantages of the system, many tasks were supposed to be performed faster and easier. Beaufort also offered automation of the tasks that were usually done manually (for example, historical reviews of different data).

The group learning processes in the PSA department necessary to adopt Beaufort were characterised as 
moderately high. We provide the description of these processes based on the textual analysis of the interview transcripts.

PSA employees interacted with the system very actively in their day-to-day task performance. They were mainly busy with operating the basic modules of Beaufort: sick leave administration, time registration, salary mutations, and report generation. These activities became routine and were mostly based on replications of instructions in using the system. The majority of the employees worked with those modules for the whole working day. Searching for new techniques and possibilities in Beaufort was rather exceptional. Two PSA members were officially assigned to search for new procedures in the system that would lead to more efficient ways of processing and administrating the data. Others were involved in such creative use occasionally, upon special request.

They used to reflect critically upon their experience with the system. Every morning they discussed different problems in use during special sessions. They had special notebooks in which they notified every nuance in Beaufort that had to be discussed. It led, for example, to the long chat about rules for sending the salary data away. In the beginning, the system used to make some inexplicable errors (mixing the numbers up, or miscalculating working hours). An employee who first discovered that immediately pointed out those errors. Everybody felt free to declare their individual difficulties and lack of skills in the use of some modules, especially "Informer".

New knowledge about system use within the PSA department was externalized mainly through the initiative of the employees themselves. 'Advanced' members, those who had high skills in software use, demonstrated the most difficult operations. One of them led two sessions on how to use the "Informer" module. She composed the content of those sessions herself based on her own experience. Another person developed special manuals for internal PSA use about tips in time registration. They felt themselves responsible for providing the whole department with new ideas. In the day-to-day practice, there was an informal rule of showing new possibilities (operations) in the system to the closest colleague.

Within the PSA department, we observed 'groupthink' about Beaufort. All employees shared a similar opinion about the goal of the system: they viewed the purpose of the system differently from its real idea. Thus, they shared the opinion that Beaufort was introduced because the previous system was antiquated. Just a few employees saw that the goal of the system was connected with the restructuring of the HR information in the company. When recalling the historical events of introducing Beaufort, they did not originally see any need for the new system, and could not even formulate that point. They understood the services offered by Beaufort, but mentioned that it was a complicated technology that required a lot of effort to understand and get used to. Their attitudes towards the functionality of Beaufort were positive and rather critical. They realised the advantages of Beaufort in comparison with the old system. Even while working with Beaufort step by step, they became convinced of their need for it. They thought that the content functionality of Beaufort still had room for improvement: it was necessary to adapt it more to the hospital environment (making historical reviews, flexible notification of the working hours, administration of the fringe benefits, etc.). Technical characteristics were criticised less, except the lack of a program memory and the speed of the "Informer" module. Their attitudes towards the future use of the system were split. They were enthusiastic about continuing with Beaufort for themselves, within PSA. But all of them were very pessimistic concerning implementing the long-term goal of Beaufort future use across the whole company. They found that idea absolutely non-realistic.

Some employees always took part in the activities aimed at arranging agreements within the PSA department concerning Beaufort. When suggestions were made to organise instructions about use of the "Informer" module, the employees themselves arranged that. They had many suggestions on how the system could be improved, but those ideas were not always implemented because it took too much of their energy to put the ideas into practice. For example, there was a proposal from many users to have the missing codes of different departments in the module of time registration. But it remained only a proposal.

In sum, collaborative learning processes within the PSA group members can be characterised as strong. Task-related operations with Beaufort, communicating about different aspects of it, activities oriented towards knowledge externalisation and achieving collective agreements were strong. Only the group understanding of the role and functionality of Beaufort was moderate.

Based on the observations, interviews with the end-users and project team members, we may conclude that PSA members have adopted the newly introduced system with a high level of efficiency. All employees (100\%) got used to Beaufort in accordance with the scheduled plan - within three months.

The stable use of Beaufort among PSA specialists was high along all three dimensions. The employees shared perceptions about the evident ease-of-use of Beaufort, especially regarding its main modules. The interface was perceived as not very friendly, but at the same time it was 
not difficult to operate. Task-system fit, or the usefulness of Beaufort, was estimated as high. The system played an important role in supporting the execution of tasks. In general, all tasks remained the same in comparison with the working situation with the previous system. But the efficiency of their performance became greater: less paper work, flexibility in assisting the clients, immediate availability of the necessary information. Efficacy beliefs were highly positive among the PSA workers. They were all enthusiastic concerning their capability to operate and learn about Beaufort further, without any external help.

In summary, the stable use of Beaufort by the PSA employees can be characterised as high. After three months, all PSA members worked with the different modules of the system skillfully and enthusiastically, and the system met the requirements of their job tasks.

\subsection{Sub-case 2: Beaufort and local HR managers}

The main tasks of the local personnel managers were to advance HRM policy and personnel administration within their departments. Documenting of the working leave hours of the employees was a small part of all the managerial tasks within the departments.

The local managers had never worked together as a group in order to perform HR administrative tasks, and they were never interdependent regarding those tasks.

Our investigation involved only those HR managerial employees who participated in the pilot project of Beaufort implementation from 5 different departments. They included 19 end-users of the system: 20\% male, $80 \%$ female; the average age was 36.2 years; the average period of employment in their departments was 8.5 years.

The software experience was different among all local managers. On average, 16 (out of 19) employees were used to working with IT. In one of the departments, they even introduced a self-designed HR system some years ago. However, 3 HR managers in another department were not used to working with computers.

The plan was to introduce two modules from Beaufort for decentralised use: time registration, sick leave administration. Also, the "Office Link" tool was installed. Introduction of the modules aimed at supporting two tasks of the HR managers: registration of the working hours and sick leave days for the employees. "Office Link" had to facilitate sending the multiple letters to the employees. These tasks were not the main ones for this group of users; therefore, the centrality of the system was not high.

Introducing the new IT demanded complex changes in performing the usual tasks. First, the way of task performance had to be changed: instead of filling papers in and sending them to the PSA department, the local managers had to make inputs electronically and share the information with the PSA specialists and other HR managers. Second, the content of inputs had to be changed: the managers had to learn different legal aspects of the registration of working hours or sick leave administration. Third, the responsibility for those inputs had to be transferred from the PSA specialists to the managers. Any mistakes in inputs could lead to financial complications for the departments and for Medinet. Fourth, decentralised users had to build new collaboration via the system: with the PSA specialists and with HR managers from other departments. That collaboration implied a higher level of individual responsibilities related to the authorisation and security of the shared private information of the employees.

The intensity of use of the sick leave administration module by the local managers was not high: the inputs were made on average 3-5 times a week. The intensity of use of the time registration module was moderate: once a day.

The group learning processes among the local managers in order to adopt Beaufort were weak.

The local managers were busy with the inputs on average 2-4 times a week, not more than 40-60 min a day. All inputs were similar, made in one of two modules. They did not search for new techniques in the system.

The local managers hardly communicated or discussed use of Beaufort with the aim to understand it better. Occasionally, some of them called other people whom they already knew personally, to ask about its usage. But there were no attempts to broaden the contacts and talk with other users within this group. Rare conversations mostly aimed at finding out how to 'copy' some operations. Discussing errors took place only within one department. It was related to the situation when Beaufort used to mix the months in the outgoing documents, and the employees had to correct that manually for two months. But that experience was not discussed with all decentralised users. Some of them used to compare Beaufort with the previous software experience, but at a rather general level (like "it was better and easier"). Individual difficulties were also declared only in one department, and not across the whole decentralised group. Those individual difficulties were mainly related to the users' uncomfortable feelings regarding the system.

Knowledge dissemination took place mostly between the PSA specialists and the local departments, and not across them. The local managers were waiting for external help from the PSA, but did not try to externalize knowledge themselves. There were no propositions made of how to use Beaufort in an improved, decentralised manner, only suggestions of NOT using it at all. 
The local managers understood quite correctly the idea behind Beaufort. They noted that it was introduced in order to reorganize the process of registration of HRM. But they did not see any individual need in the new system: either they were satisfied with the current ICT, or it did not bring any benefits for them. They understood how to operate the modules but found them unreasonably complicated. They also shared opinions concerning some of the Beaufort characteristics. Thus, they found that the system was not protected from wrong inputs that could lead to crucial mistakes. They doubted whether the ICT system could replace their HR work. In general, they considered Beaufort as probably useful but were disappointed by the discrepancy with a lot of expectations about it. They were very pessimistic regarding the future use of Beaufort. Their main concern was about unexpected new tasks and increasing financial responsibilities for the outcomes in the system.

Activities that aimed at getting collective agreements among decentralised users were quite intensive. They proposed improvements in the manual: they wanted it to be operationalised like "what...if". Being disappointed with the Beaufort experience, they organized evaluation sessions themselves, without plans from the project team. In two departments, they took the initiative to write a letter of intent addressing the project team with all the difficulties and problems regarding the use of Beaufort.

In summary, collaborative learning processes within a group of local managers were directed at blocking use of Beaufort. Task-related operations with Beaufort, communicating to improve its usage, externalization of ideas, the common meaning of the system, and mutual adjustment were at moderate or low levels.

We may conclude that local HR managers have not adopted the newly introduced two modules of the system in accordance with the project plan. They struggled with the implementation process, described above, for 7 months, and finally decided to terminate it. All end-users (100\%) shared the opinion that it was necessary to close the project until 'better times'.

We provide the data on the level of stable use of Beaufort by the local managers by the time after they had been using it for six months.

The stable use of Beaufort among HR managers was mostly low. The majority of the users shared perceptions about the difficulties-of-use of Beaufort. The interface was perceived as not friendly, with many screens and lots of unnecessary icons. Task-system fit was estimated as low. The system did not facilitate the usual tasks, on the contrary, it brought the necessity to learn and perform new tasks which were not important for the end-users. Efficacy beliefs were moderate among the HR managers. They believed in the possibility to operate the system consistently IF the system would meet their requirements. But after six months of operating with two modules, they still felt uncomfortable with Beaufort and were afraid to make inputs without external help.

In summary, the stable use of Beaufort by the local managers can be characterised as low. After six months, all of the decentralised users still did not work with two modules of the system skillfully, enthusiastically, and taskconsistently.

\section{Conclusions}

Introducing a similar type of IT in a Dutch hospital in two different settings has led to the opposite results: it was successful within PSA, sub-case 1 , but failed in sub-case 2, decentralised use, after a few pilots. We have applied a group learning perspective on groupware implementation in this case, which is understood as interactional group processes aimed at improving the adoption of a newly introduced IT.

This perspective provides us with interesting notions about the reason for the different outcomes between the two sub-cases. In sub-case 1, the group learning processes were relatively strong, especially group reflecting behavior and knowledge dissemination behavior, and were oriented towards adopting Beaufort. In the second sub-case, the group learning processes were weak, especially the level of group reflecting behavior, knowledge dissemination behavior, and activities for sharing understanding, and were oriented towards freezing the whole project. This difference provides grounds to conclude that groupware implementation in sub-case 2 could have benefitted if group learning processes had occurred. This raises the question about how this could have been achieved.

At the level of a group itself, the collaboration-support factors should be taken into consideration. The PSA case involved only a few changes in tasks, while the level of task division and interdependence was high and established before the introduction of the system. In the decentralised case, tasks distributed over different departments were affected in a subtle and not quite anticipated way. The content (identity) of those tasks became rather new for the targetted employees, who called for a new level of responsibilities for their performance. Managing personnel data came to be quite a sensitive issue regarding privacy and the security of the information. In the PSA case, groups responsible for tasks affected by the new system had a group identity and experience in collaboration. In the 
distributed case, the group members did not have any experience in collaboration.

What should we advise, based upon our study, those responsible for groupware implementation in practice? We suppose that before implementing a groupware system, there is a need to create collaboration among its users. This doesn't mean that groups of users must have all collaborative prerequisites in advance in order to adopt the system. We strongly believe that group processes do improve through the use of groupware. But at the same time, essential group characteristics must be established in advance. These include interdependence, individual accountability, and task division. Such prerequisites prepare the basis for group learning processes, through which the implementation of groupware, in our view, develops successfully.

\section{References}

[1] Bardram, J. (1998). Designing for the dynamics of cooperative work activities. Proc. CSCW'98, 89-98.

[2] Bondarouk, T. \& Sikkel, K. (2001). A learning perspective on groupware implementation, Proc. IRMA 2001 (Toronto, May 2001), Hershey, PA: Idea Group Publishing, 701-703.

[3] Bondarouk, T. \& Sikkel, K. (2002). Implementation of collaborative technologies as a learning process. In. J. Cano Martínez (Eds.), Critical Reflections on Information Systems - A Systemic Approach. Idea Group Publishing, Hershey, PA (in press).

[4] Campion, M.A., Papper, E.M., \& Medsker, G.J. (1996). Relations between work team characteristics and effectiveness: a replication and extension. Personnel psychology, 49, 429 - 452.

[5] Cannon-Bowers, J.A., Tannenbaum, S.I., Salas, E., \& Volpe, C.E. (1995). Defining competencies and establishing team training requirements. In: R.A.Guzzo and E.Salas (Eds.), Team effectiveness and decision making in organizations, 333 - 380, Jossey-Bass, San Francisco.

[6] Druskat, V.U., \& Kayes, D.C. (2000). Learning versus performance in short-term project teams. Small group research 31 (3), 328-353.

[7] Edmondson, A. (1999). Psychological safety and learning behavior in work teams. Administrative Science Quarterly, 44 (2), 350-383.

[8] Elliot, R. (1996). Discourse analysis: exploring action, function and conflict in social texts. Marketing Intelligence \& Planning, 14 (6), 65 - 68.

[9] Gardner, M. (1993). The great Samoan hoax. Skeptical Inquire, 17, $131-135$.
[10] Gill, R. (1996). Discourse analysis: practical implementation. In J.T.E.Richardson (Eds.), Handbook of Qualitative Research Methods, 141 - 156.

[11] Grant, D., Keenoy, T., \& Oswick, C. (2001). Organisational discourse. International Studies of Management \& Organisation, 31 (3), Fall 2001, 5 - 24.

[12] Hackman, J.R. (Eds.) (1990), Groups that work and those that don't. Jossey-Bass, San Francisco,

[13] Hardy, C. (2001). Researching organizational discourse. International studies of management \& organization, 31 (3), 25 47.

[14] Hendriks, P. (1999). Why share knowledge? The influence of ICT on the motivation for knowledge sharing. Knowledge and Process Management, 62, 91-100.

[15] Hettinga, M. (2002).Understanding evolutionary use of groupware. Telematica Instituut, The Netherlands.

[16] Kasl, E., Marsick, \& Dechant (1997). Teams as learners. J. Applied Behavioral Science 33 (2), 227-246.

[17] Kim, D.H. (1993). The link between individual and organizational learning. Sloan Management Review, 35 (1), 37 50 .

[18] Khoshafian, S., \& Buckiewicz, M. (1995). Introduction to groupware, workflow, and work-group computing. New York, NY: John Wiley \& Sons.

[19] Kolb, D. A. (1984). Experiential learning. Experience as the source of learning and development. School of Business, Public Aministration and Technology. Prentice-Hall, Englewood Cliffs, N.J.

[20] Lincoln, Y.S., \& Guba, E.G. (1985). Naturalistic inquiry. Beverly Hills, CA: Sage.

[21] Marshall, H., \& Wetherall, M. (1989). Talking about career and gender identities: a discourse analysis perspective. In $\mathrm{S}$. Skevington and D.Baker (Eds.), The social identity of women. London: Sage, 76 - 98.

[22] Marsick, V. (1987). Learning in the workplace. London; Croom Helm.

[23] Mulder, I. \& Swaak, J. (2000). How do globally dispersed teams communicate? Telematica Instituut, The Netherlands.

[24] Onstenk, J.H.A.M. (1995). Human Resources Development and On-the-job Learning. In M. Mulder, W.J. Nijhof \& R.O. Brinkerhoff (Eds.), Corporate Training for Effective Performance, Boston, MA: Kluwer Academic Publishers.

[25] Orlikowski, W.J., \& Gash, C. (1994). Technological frames: making sense of information technology in organisations. ACM Transactions on Information Systems 12 (2), 174-207.

[26] Oswick,C. (2000). Discourse, organizations and organizing: concepts, objects and subjects. Human Relations, 52 (9), 1115 24.

[27] Potter, J., \& Wetherell, M. (1987). Discourse and social psychology. London: Sage.

[28] Ruel, H. (2001). The non-technical side of office technology. Enschede: Twente University Press.

[29] Ruel, H., \& Bondarouk, T. Organizational climate for innovation implementation and ICT appropriation: exploring the relationship through discourse analysis. Submitted for publication. 
[30] Schippers, M. C., Den Hartog, D. N., \& Koopman, P. L. (2001). Reflexivity in teams. In Proc. Academy of Management Conference 2001, (Washington DC, August 2000).

[31] Sinclair, J.M., \& Coulthard, R.M. (1975). Towards an analysis of discourse: the English used by teachers and pupils. London: Oxford University Press.

[32] Stahl, G. (2000). A model of collaborative knowledge building. Proceedings of Fourth International conference of the Learning Sciences, Ann Arbor, MI, 70-77.

[33] Tucker, A.L., Edmondson, A.C., \& Spear, S. (2001). When problem solving prevents organizational Learning. Harvard Business School working paper 01-073.

[34] Van Dijk, T.A. (Eds.), (1985). Discourse and communication: new approaches to the analysis of mass media discourse and communication. Berlin: Walter de Gruyter.

[35] Woodilla, J. (1998). Workplace conversations: the text of organizing. In D.Grant, T.Keenoy, and C.Oswick (Eds.) Discourse and Organisation, 31 - 50. London: Sage

[36] Wulf, V. (1998). Evolving Cooperation: Studies on Organizational Change when Applying Groupware. In P. Mambrey, M. Paetau, W. Prinz, and V. Wulf (Eds.) Self-Organization: A Challenge to CSCW. Kluwer, Dordrecht.

[37] Zajacova, A. (2002). The background of discourse analysis: a new paradigm in social psychology. Journal of Social Distress and the Homeless, 11(1), 25 - 40. 